\title{
Research on Entrepreneurial Ability Model of College Students in Big Data Era_ A Case Study of "San Xun Flower Shop"
}

\author{
Heming Sun \\ School of Foreign Languages, Quanzhou Normal University, Quanzhou, 362000 \\ Fujian, P. R. China \\ Caiying Wang (Corresponding author) \\ School of Foreign Languages, Quanzhou Normal University, Quanzhou, 362000
}

Fujian, P. R. China

Received: December 13, 2021

Accepted: January 19, 2022 Published: January 21, 2022

doi: 10.5296/jsss.v8i2.19490

URL: https://doi.org/10.5296/jsss.v8i2.19490

\begin{abstract}
Innovation and entrepreneurship education is a new requirement for education under the situation of rapid social development in the new era. It is an important quality education in the current education system, and its essence is a skill education. Since the concept of "mass innovation, national entrepreneurship" was put forward, the innovation and entrepreneurship education for college students has been carried out in China, and some results have been achieved. But from the overall point of view, the innovation and entrepreneurship education of college students in China should be improved, and a specific, complete and scientific education system has not yet been formed. On this basis, this article analyzes the current problems in the education of cultivating college students' innovation and entrepreneurship ability according to the experience of the project of "San Xuan Flower Shop", and proposes some suggestions for reference.
\end{abstract}

Keywords: college students, innovation and entrepreneurship, ability training, talent cultivation

The world has entered the era of big data. With the promotion of national big data policies and the development of big data technology, traditional business models are being rewritten, and entrepreneurial opportunities in big data-related fields are emerging in large numbers.

As a new force for social development, college students have natural interests and advantages 
in digital internet. The advent of the era of big data has also brought many new ideas to the study and employment of college students. In the wave of "mass entrepreneurship and innovation", in addition to directly participating in entrepreneurship in the big data industry, college students can also make full use of big data to try innovation and entrepreneurship in many traditional fields. However, at present, the proportion of Chinese college students participating in entrepreneurship is low and the success rate of entrepreneurship is lower (Xu \& Zhao. 2018: 1). One of the main reasons is the insufficient entrepreneurial ability of college students. This reflects to a certain extent that the cultivation of entrepreneurial talents in colleges and universities in China still needs to be improved.

\section{Problems Existing in the Innovation and Entrepreneurship Education of University Students Driven by Projects}

(1) Lack of resources

At the current stage, my country's innovation and entrepreneurship education is heavily dependent on innovation and entrepreneurship education resources. When college teachers carry out innovation and entrepreneurship education activities, most of them unilaterally instill knowledge in students. Although major colleges and universities responded positively, only a small number of universities devotes a small part of the available funds to college students' innovation and entrepreneurship education. Some universities have also established innovation and entrepreneurship incubation bases or incubation centers in accordance with the requirements, but they have not started the project when they launched the project.

(2) Students' low innovative ability

The low innovation ability of college students at the current stage is a common problem for college students. Analysis of the reason shows that the main reason is that the majority of teachers are deeply influenced by traditional educational concepts. Under this influence, teachers did not pay attention to cultivating students' innovation ability and innovative skills in the classroom, and paid too much attention to it. Complete the teaching task. In addition, some teachers have little knowledge of innovation and entrepreneurship, and students cannot fully grasp the teaching content, which seriously hinders teachers from carrying out innovation and entrepreneurship education activities and has an adverse impact on student development.

(3) Lack of practice platform

The analysis of the status quo of college students' innovation and entrepreneurship education shows that it has a strong practicality, but most colleges and universities seriously lack an innovation and entrepreneurship practice platform, which is not conducive to the development of innovation and entrepreneurship education. In this context, even if some students have good entrepreneurial ideas, they cannot be practiced, and innovation and entrepreneurship education is struggling. Some students do not understand innovation and entrepreneurship projects and face many difficulties in selecting topics. This is the main reason why innovation and entrepreneurship achievements cannot be implemented. In addition, from the analysis of involvement, innovation and entrepreneurship education in colleges and universities contains a lot of content, and the links are closely connected. Although universities have formed a complete system, it is difficult to meet the needs of 
innovation and entrepreneurship education, and there is a lack of comprehensive policies. Besides, the universities pay too much attention to the application of innovation and entrepreneurship education and does not pay attention to project construction, and does not pay attention to guiding students to implement it, causing students to be in a state of extreme confusion.

\section{Project introduction of "San Xan Flower Shop"}

With the popularization of the Internet and the rapid development of e-commerce, more and more people are choosing to shop online. This includes the purchase of daily consumer goods and the purchase of gifts. When ordering gifts online, merchants can directly send the gifts. To customers, it not only saves the time of personally going to the store to select gifts, but also avoids the inconvenience of giving gifts in person. Among the many gifts, flowers are undoubtedly one of the best gift choices for people. They can be given as gifts on almost any festival or special occasions.Ordering flowers online has the characteristics of time-saving, trouble-saving, and cost-saving, so it gradually gains popularity among people especially college students. Under this situation, online flower shops undoubtedly have huge development prospects in the e-commerce market.

The 21st century is the era of the Internet, people from all walks of life are casting their sights on this emerging field. Flower shop owners may wish to participate in e-commerce, whose characteristics are suitable for flower transactions and strengthen their competitiveness. Flower shops can also carry out brand chain sales and other forms.

The flower shop has flexible operating hours, which can meet the needs of customers at different times; the decoration of the flower shop can provide consumers with a good shopping environment and make consumers feel happier; the flower shop on campus can make teachers, students and consumers enjoy faster service.

\section{Research Plan and Results}

\subsection{Research Purpose}

Through the investigation of online and offline purchases of flowers by college students, we want to learn about the trend, the types and standards of college students' purchase of flowers.

Research methods: Face-to-face interviews are conducted with teachers, college students, and some school employees, etc.

Interviewees: college students (including freshman to senior students and some graduate students).

\section{Analysis of the Reasons Why College Students Buy Flowers Online and Offline}

Through interviews, most students who have experienced online flower purchases stated that the main reasons they choose online flower purchases are the low prices and the variety of flowers. Most college students choose to buy flowers online because they can have discounts for the flowers compared to physical stores. What's more, online shopping is more convenient,because they offer anytime, anywhere purchasing opportunity.

The survey showed that the main reasons for college students who did not try to buy flowers online were their worries about the freshness of flowers, distrust of website security, fear of being deceived, and unsafe payment. 
Offline purchases are mostly based on temporary purchases or purchases based on lover's hobbies, and some respondents are based on the need to decorate the room.

\section{College Students' Choice of Channels for Buying Flowers}

(1) Obtained channels

According to the survey results, the websites where college students buy flowers are mainly Taobao and Pinduoduo, and some online platform which are introduced by friends. The university campus gathers students from all over the world, with similar ages and similar consumption habits.Consequently, due to the influence of roommates, classmates, fellow villagers, and friends, the herding phenomenon is more obvious. In the past two years, community group transactions have entered the campus, and some students have begun to purchase flowers on platforms such as Meituan Optimal.

(2) Reasons for selecting online and offline stores

College students have their own ability to control money within a certain amount, and they have a clear objectives what to buy. Even if they buy flowers, they also have higher requirements for online stores. When they buy flowers, they give the first priority to high popularity and good reputation for online and offline stores.

\section{Characteristics of Buying Behavior of College Students Buying Flowers}

(1) The type of goods or services purchased

From the results of our survey, the types of flowers purchased by college students mainly include various types of roses and potted plants, carnations and some dried flowers. According to different festivals, some gift boxes of flowers will be purchased to send to friends and relatives.

This reflects a way for college students to express affection, love and friendship with flowers when they are not studying.

(2) The frequency and amount of purchase

Through research, the frequency of college students buying flowers is mostly 5-8 times a year, and a small number of people buy flowers more frequently. The prices are from 10 yuan to 100 yuan.

(3) Price expectations

From the results of our survey, prices are their preference. On holidays, orders will be placed online in advance. From this point of view, contemporary college students have a more rational concept of flower consumption. They not only want to enhance the mood of life, but also pay attention to the price and quality of commodities.

\section{Analysis of the Characteristics of Online and Offline Flower Purchases by College Students}

(1) Gender characteristics of college students who purchase flowers

After research, it is found that there are slightly more boys than girls buying flowers online, especially during festivals, such as Valentine's Day, March 8th, and Qixi Festival(Chinese Valentine's Day). On campus, boys send flowers to girls more frequently than girls. This may be one of the reasons why more boys buy flowers online than girls. Girls mostly consume more small-potted plants online. The frequency of buying flowers in off-line stores is similar 
to that of boys and girls, and the randomness is greater. If beautiful flowers are seen, they may have the urge to buy.

(2) Age characteristics of college students buying flowers

College students are between the ages of 17-25, and most undergraduate translators are between 18 and 22 years old. After investigating them, we can see that the number of sophomores and juniors buying flowers is more than that of freshmen, seniors and graduate students. Therefore, it can be seen that age also has a certain influence on online shopping. Sophomores and juniors are the people who frequently purchase flowers by online shopping.

(3) Characteristics of college students' ability to pay for flowers

Most college students' living expenses come from their parents and part of their part-time jobs. Therefore, the living expenses of students are basically concentrated between 1000 and 1500 , and some students are higher or lower than this range. Therefore, the purchase of flowers is within the purchasing power range, mostly between 50-100 or single purchase.

\section{Evaluation of College Students on Buying Flowers}

(1) Worries about buying flowers online

The survey indicated that students are more concerned about the quality of online flowers, payment security, after-sales service, and timeliness of delivery. Pay particular attention to the freshness of flowers and delivery time.

(2) To-be-improved aspects

The survey results show that the freshness and packaging of flowers are particularly concerned, and some students said they have had a very unpleasant experience of buying flowers online. It also stated that it will not buy online during important festivals, but will choose to buy offline.

There are many online purchase channels, if there is a flower shop specifically for college students, it would be welcomed. I hope the flower shop can popularize some flower knowledge and some flower language.

(3) Willingness to buy in the future

For the purchase of flowers, most college students still have a strong desire to buy flowers. Except for some traditional Chinese medicine festivals, it is indeed feasible to buy flowers online. The advantages of convenience, variety of goods, and low prices all attract college students to buy online. The interviewed college students believe that online shopping has broad prospects, large room for development, and easy acceptance. One plausible explanation of the phenomenon is that the past two decades witness the prosperity of internet in China and economic development.

\section{Conclusion}

(1) Facing the current high risk of entrepreneurship, from the analysis of college student entrepreneurs themselves, it is concluded that the main reasons are lack of funds, lack of experience, lack of market awareness, and lack of entrepreneurial thinking. How to solve the difficulties of capital, experience, market, thinking, and confidence is mainly to effectively improve the success rate of undergraduate entrepreneurship(Yao Kai \& Li Sizhi. 2021).

(2) Kozlinska(2012) reckoned that "the entrepreneurial ability of college students" is 
divided into three dimensions: knowledge, skills, and attitude. We also learn a lot from this project. For example, we improve entrepreneurship organization and management ability, which is a comprehensive ability. College students should not only carry out theoretical study from books, but also learn experience and lessons from practice, and continue to reflect and improve.

(3) The purchasing potentiality of college students is huge

Although economic conditions constrain the consumption behavior of college students, the amount of consumption of flowers is relatively low, and flowers are a way to cultivate college students' interest in life and express their love. Therefore,the potential is huge.

(4) Flower shop owners participate in e-commerce, and their characteristics are suitable for flower transactions and strengthen their competitiveness. Flower shops can also carry out brand chain sales, overnight florists and other forms.

(5) Provide corresponding after-sales service. After-sales service is mainly embodied in teaching consumers the knowledge of maintenance and preservation, frequent visits to customers, grasping new requirements and trends of their consumption, and timely replacement of fresh flowers to customers with rental business, etc. Flower shop services must take customer complaints seriously. Once a customer has quality problems with flower products, they must be properly dealt with so that customers are satisfied.

(6) According to the on-campus market, provide different activities and floral designs for college students or open an unmanned flower supermarket.

(7) Now with the development of the times, the needs of customers have gradually changed from "what do I want" to "what do you have", which requires a store to obtain enough exposure traffic to show its own superior attributes, public account, The rational use of platforms such as Ruanwen, Xiaohongshu, and Zhihu, the support of online takeaway purchase platforms, and their own clear positioning of products are the keys to the success or failure of a store. The second is that the accumulation of private domain traffic will increase the value of my future career. By establishing a WeChat group, I can not only consume some inventory, but also make the impossible possible.

(8) Innovation and entrepreneurship education is a new requirement for education under the situation of rapid social development in the new era in China. It is an important quality-oriented education in the current education system, and its essence is a kind of skill education. Since the concept of "mass innovation and entrepreneurship for all" was put forward, the innovation and entrepreneurship education for college students in a vast majority of Chinese universities has been carried out in full swing, and has made some achievements. However, on the whole, the innovation and entrepreneurship education of college students in our country is still on the initial stage, and a specific, complete and scientific education system has not yet been formed.

\section{Acknowledgements}

This paper is supported by 2019 Quanzhou Normal University Innovation and Entrepreneurship Project for College Students "San Xuan Flower Shop"(三旬花店) and 2021 Quanzhou Normal University Teaching Reform Project "Research on Online and Offline 
Mixed Teaching of English Advanced Writing"(No.: 116).

\section{About Authors}

SUN Heming is a student of School of Foreign Language, Quanzhou Normal University.

WANG Caiying is associate professor of Quanzhou Normal University. She mainly teaches "English Writing" to undergraduates. She has published about thirty papers.

\section{References}

KOZLINSKAI. (2012). Fundamental View of the Outcomes of Entrepreneurship Education[J]. SSRN Electronic Journal, 90, 3. https://doi.org/10.2139/ssrn.2188251

XU \& ZHAO. (2018). A rational analysis of improving the success rate of college students' entrepreneurship[J]. Innovation and Entrepreneurship Education, 4, 1-5.

YAO \& LI. (2021). Research on Entrepreneurial Ability Model of College Studets in Big Data Era[J]. Heilongjiang Education(Theory \& Practice), 11, 1-4.

\section{Copyright Disclaimer}

Copyright for this article is retained by the author(s), with first publication rights granted to the journal.

This is an open-access article distributed under the terms and conditions of the Creative Commons Attribution license (http://creativecommons.org/licenses/by/4.0/). 